\title{
ESTIMATION OF PARAMETERS AND SELECTION OF MODELS APPLIED IN ADSORPTION
}

\author{
I. C. B. Amador ${ }^{\mathrm{a}}$, \\ B. M. Viegas ${ }^{\mathbf{b}}$, \\ E. N. Macêdo ${ }^{\mathrm{a}}$, \\ K. G. P. Nunes , \\ L. A. Féris ${ }^{c}$, \\ and D. C. Estumano ${ }^{d}$ \\ ${ }^{a}$ Federal University of Para \\ Faculty of Chemical Engineering \\ Postcode 66075-110, Belém, Pará, Brazil \\ Abstract \\ ianka.cristine@gmail.com.br \\ ${ }^{b}$ Federal University of Para \\ Graduate Program in Process Engineering \\ Postcode 66075-110, Belém, Pará, Brazil \\ ${ }^{\mathrm{c}}$ Federal University of Rio Grande do Sul \\ Departamento of Chemical Engineering \\ Postcode 90040-040, Porto Alegre, Rio Grande \\ do Sul, Brazil \\ ${ }^{\mathrm{d}}$ Federal University of Para \\ Faculty of Biotechnology \\ Postcode 66075-110, Belém, Pará, Brazil \\ Received: Sept 11, 2020 \\ Revised: May 07, 2021 \\ Accepted: May 24, 2021 \\ The modeling of complex phenomena such as adsorption often requires the \\ determination of parameters that cannot be directly measured and, therefore, \\ must be estimated. An important point is related to the analysis of the \\ inverse problem as a method of estimating parameters and selecting models. \\ In view of this, this work aims to apply the Monte Carlo method via \\ Markov Chains (MCMC) as a technique for solving the inverse problem of \\ estimating fixed-bed adsorption parameters using analytical models \\ proposed in the literature. In addition, this work aims to select the best \\ model through the statistical metrics Akaike, corrected Akaike and \\ Bayesian Information Criterion. The use of the Bayesian approach allowed \\ the analysis of the convergence of the chains, as well as selected the best \\ model to represent the experimental data obtained from the literature. \\ Keywords: parameter estimation; selection of models; adsorption

\section{NOMENCLATURE} \\ A Clark constant, dimensionless \\ $\Delta \mathrm{C} \quad$ concentration variation, $\mathrm{mg} \mathrm{L}^{-1}$ \\ $\mathrm{C}_{\text {break }}$ rupture concentration, $\mathrm{mg} \mathrm{L}^{-1}$ \\ $\mathrm{C} / \mathrm{C}_{0}$ concentration vector, $\mathrm{mg} \mathrm{L}^{-1}$ \\ $\mathrm{C}_{0} \quad$ initial concentration, $\mathrm{mg} \mathrm{L}^{-1}$ \\ $\mathrm{z} \quad$ Cartesian coordinate, $\mathrm{cm}$ \\ $\mathrm{t} \quad$ ellipses eccentricity, b/a \\ $\mathrm{k}_{\mathrm{TH}} \quad$ Thomas kinetic constant, $\mathrm{mL}(\mathrm{mg} \cdot \mathrm{min})^{-1}$ \\ $\mathrm{q}_{0} \quad$ maximum amount adsorbed, $\mathrm{mg} \mathrm{g}^{-1}$ \\ W mass of the adsorbent, $g$ \\ Q column flow, $\mathrm{mL} \mathrm{min}^{-1}$ \\ $\mathrm{k}_{\mathrm{YN}} \quad$ Yoon-Nelson kinetic constant, $\min ^{-1}$ \\ n Freundlich isotherm constant \\ $\mathrm{r} \quad$ Clark constant, $\mathrm{min}^{-1}$ \\ $\mathrm{K}_{\mathrm{T}} \quad$ mass transfer coefficient, $\min ^{-1}$ \\ $\mathrm{Q}_{\mathrm{a}} \quad$ volumetric flow rate, $\mathrm{cm}^{3}\left(\mathrm{~min} \cdot \mathrm{cm}^{2}\right)^{-1}$ \\ $\mathrm{q}_{\mathrm{y}}$ maximum adsorption capacity, $\mathrm{mg} \mathrm{g}^{-1}$ \\ $\mathrm{a}_{\mathrm{y}} \quad$ Yan coefficient, dimensionless \\ w search step \\ $\mathrm{u}$ random number \\ AIC Akaike criteria \\ AIC $_{\text {Corr }}$ Fixed Akaike Criterion \\ BIC Bayesian Information Criterion

\section{Greek symbols} \\ $\varepsilon_{\mathrm{p}} \quad$ perturbation, Eq. (7) \\ $\varepsilon \quad$ random variable $\mathrm{N}(0,1)$ \\ $\theta$ parameter vector \\ $\sigma_{\text {meas }}^{2}$ measure variance \\ $\alpha$ probability of acceptance of Metropolis- \\ Hastings \\ $\tau \quad$ time to reach $50 \%$ break, min $^{-1}$ \\ $\theta^{*} \quad$ candidate vector

\section{Subscripts} \\ t state variable counter \\ j counter parameters \\ NP total parameters \\ $\mathrm{TF}$ total state variables
}


$\mathrm{T}$

transposed

\section{INTRODUCTION}

The adsorption describes the mass transfer phenomenon present in several separation processes applied in the most diverse areas of the industry (Bonilla-Petriciolet et al., 2017). The adsorption research constantly requires forecasting and programming the process mainly in continuous systems, such as fixed bed adsorption (Weber, 1987).

On a large scale, the fixed-bed is the best proposal in the treatment of large volumes of effluents and in adsorption-desorption cycles (Nascimento et al., 2014). These systems are represented graphically by the breakthrough curves and the analysis of this curve is commonly used to predict the performance of fixed adsorbent beds (Luz, 2012). However, it is quite difficult to predict the dynamics of the system, as certain parameters of the models cannot be determined experimentally directly, so there is a need to apply statistical techniques to estimate them.

Some kinetic models have been proposed to simulate the dynamics of the breakthrough curve. Among them, the models of Thomas, Clark, YoonNelson and Yan stand out, each one proposed according to different hypotheses, but which present a simple formulation and analytical solution. For this reason, they are widely used in the study of adsorption (Ang et al., 2019; Jain et al., 2019; Jaria et al., 2019; Borna et al., 2016, Radhika et al., 2018).

From the application of the reported models, it is possible to infer which mechanisms are present in the adsorption process without the need to propose and solve more complex equations that involve partial differential equations. However, the simplifications of each model differ in their origin, being essential to know the hypotheses that were considered in each mathematical model.

Another practical point concerns the parameters of the equations. Most of the parameters of these models are estimated by linear and non-linear regression techniques (Shanmugam et al., 2016; Liu et al., 2019; Nakkeeran et al., 2018). The first strategy, although easily applicable, sometimes involves modifying the intrinsic interpretation of the parameters, which may violate the assumptions of variance and normality of the residuals by linearizing the data (Lima, 2009).

Therefore, it opted mainly for the application of non-linear regression through usual algorithms, based on the least-squares method, which is a frequentist approach (Naveira-Cotta, 2009). In parallel to this, the Bayesian approach can combine the observed value of the rupture curve, formally called as a likelihood function, with the information of the a priori distribution of the parameters. This prerogative becomes a premise in solving the inverse parameter estimation problem.
In Bayesian inference, the posterior probability distribution of a parameter contains all the probabilistic information about that parameter (Elhers, 2001). However, it is often difficult to obtain the analytical solution of the posterior probability distribution, especially for non-linear problems. In these cases, computational techniques such as the Monte Carlo method via Markov Chain (MCMC) allow approximating aspects of probability distributions to later ones that cannot be directly calculated. Such probabilities can be represented by generating samples in a sequential process (Ravenzwaaij et al., 2018).

This work aims to apply the MCMC method using the Metropolis-Hastings acceptance/rejection algorithm as an alternative proposal for solving the inverse parameter estimation problem in the fixed bed column adsorption process using classical analytical models in order to estimate the breakthrough curve of sevoflurane in activated carbon.

\section{DIRECT MODEL - ADSORPTION}

The rupture curve is described in terms of the ratio between the concentration of adsorbate at the exit of column $\mathrm{C}$ of height $\mathrm{z}$ by the initial concentration $\mathrm{C}_{0}$ versus time $\mathrm{t}$ or volume of treated liquid. The mathematical formulations of the analytical models that describe the fixed-bed adsorption studied in this work are presented below.

\subsection{Thomas model}

The most popular kinetic equation was formulated by Thomas (1944), commonly used in order to estimate the maximum adsorption capacity of the adsorbent. This mathematical model was proposed to describe the exchange of ions in a column of zeolites or any solid carbonaceous, resinous, and mineral substance capable of exchanging ions with the solution in which it is immersed. (Thomas, 1944). The model is described by Eq. (1):

$$
\frac{\mathrm{C}}{\mathrm{C}_{0}}=\frac{1}{1+\exp \left(\frac{\mathrm{k}_{\mathrm{th}} \mathrm{q}_{\mathrm{th}} \mathrm{W}}{\mathrm{Q}}-\mathrm{k}_{\mathrm{th}} \mathrm{C}_{0} \mathrm{t}\right)}
$$

where $\mathrm{k}_{\mathrm{TH}}\left(\mathrm{mL} \mathrm{mg}-1 \cdot \mathrm{min}^{-1}\right)$ is a kinetic constant, $\mathrm{q}_{0}$ (mg $\mathrm{g}^{-1}$ ) is the maximum adsorbed amount of adsorbate, W (g) the mass of the adsorbent, and Q $\left(\mathrm{mL} \mathrm{min}^{-1}\right)$ the column flow. The mathematical formula that gives rise to this model assumes that the adsorption follows the Langmuir isotherm and is described by a reversible reaction of pseudo-secondorder (Chu, 2010).

This means that the adsorption rate is controlled mainly by the reaction that occurs on the surface of the material, disregarding the resistances along with the adsorbent solid, that is, the resistances within the 
flow, interparticle, and/or intraparticle. However, not all adsorption phenomena are limited by the reaction kinetics. This discrepancy between the model's hypotheses and the nature of the experimental data can lead to greater errors in the curve fit (Aksu and Gönen, 2004).

\subsection{Yoon-Nelson model}

As reported in the literature, the Yoon-Nelson model assumes that the probability of adsorption of an adsorbate molecule is inversely proportional to the surface coverage and the probability of bed rupture. (Mthombeni et al., 2018; Bhaumik et al., 2013; Borna et al., 2016,). This fact is acceptable, since the greater the rupture and the occupied area, the lower the absorption rate. This simplistic characteristic extends to the model itself, which does not require the characteristics of the adsorbent and adsorbate or the physical properties of the adsorption bed as input parameters (Aksu and Gönen, 2004), as explained in Eq. (2):

$$
\frac{\mathrm{C}}{\mathrm{C}_{0}-\mathrm{C}}=\exp \left(\mathrm{k}_{\mathrm{YN}} \mathrm{t}-\tau \mathrm{k}_{\mathrm{YN}}\right)
$$

where $\mathrm{k}_{\mathrm{YN}}$ is Yoon-Nelson kinetic constant $\left(\mathrm{min}^{-1}\right)$, and $\tau\left(\mathrm{min}^{-1}\right)$ the time needed to reach $50 \%$ rupture. It is worth mentioning that the authors proposed the model for the adsorption of steam or gases in adsorbent solids (Borna, 2016).

\subsection{Clark model}

Clark's model was proposed to describe the performance of the adsorption of organic compounds in columns filled with granular activated carbon. The model was obtained from a mass balance for the fluid and solid phase of the bed in which the following hypotheses were considered (Clark, 1987):

1. The resistance to mass transfer in the outer film is a controlling step in the process;

2. All adsorbate is removed at the end of the bed considering the shape of the constant mass transfer zone;

3. The adsorption equilibrium is described by a Freudlich isotherm.

The model is described for Eq. (3):

$$
\frac{\mathrm{C}}{\mathrm{C}_{0}}=\left(\frac{1}{1+\operatorname{Aexp}(-\mathrm{rt})}\right)^{\frac{1}{\mathrm{n}-1}}
$$

where $\mathrm{n}$ is Freundlich isotherm constant, $\mathrm{A}$, and $\mathrm{r}$ $\left(\mathrm{min}^{-1}\right)$ were are constant in the model grouped according to the mass transfer coefficient $\mathrm{K}_{\mathrm{T}}\left(\mathrm{min}^{-1}\right)$ and the volumetric flow rate per unit area of the cross section $\mathrm{Q}_{\mathrm{a}}\left(\mathrm{cm}^{3} \mathrm{~min}^{-1} \mathrm{~cm}^{-2}\right)$, as well as the concentration of $\mathrm{C}_{\text {break }}$ break and $\mathrm{t}_{\text {break }}$ break time as follows in Eq. (4) and (5):

$$
\mathrm{r}=(\mathrm{n}-1) \frac{\mathrm{K}_{\mathrm{T}}}{\mathrm{Q}_{\mathrm{a}}} \frac{\mathrm{dz}}{\mathrm{dt}}
$$

$$
A=\left(\frac{C_{0}^{n-1}}{C_{\text {break }}^{n-1}}-1\right) \exp \left(\mathrm{rt}_{\text {break }}\right)
$$

In the development of this model, the law of conservation of mass was proposed along the spatial axis disregarding the term of accumulation. Unlike the Thomas model, this new strategy does not directly reflect the time difference between $\mathrm{C}$ and $\mathrm{C}+\Delta \mathrm{C}$ (Xu et al., 2013), but considers that the adsorption speed $\mathrm{dz} / \mathrm{dt}$ varies over time. This last simplifying step allows to simulate the breakthrough curve as a function of time. Therefore, this model is justified as a pseudo stationary.

\subsection{Yan model}

One of the most recent models was proposed by Yan et al. (2001) as an adaptive proposal to adequately describe the kinetics of metal removal by a biosorption column for one or more components. Equation (6) describes the model:

$$
\frac{C}{C_{0}}=1-\frac{1}{1+\left(\frac{C_{0} Q t}{q_{y} W}\right)^{a_{y}}}
$$

where $\mathrm{q}_{\mathrm{y}}$ is maximum adsorption capacity $\left(\mathrm{mg} \mathrm{g}^{-1}\right)$, and $\mathrm{a}_{\mathrm{y}}$ is the dimensionless regression coefficient of the model.

The objective of the model is to minimize the error of the Thomas model from an empirical approach without disregarding the estimate of the maximum bed capacity. However, the new proposal tries to overcome the deficiency of the concentration prediction at zero time or zero volume, since the Thomas model has a fixed value when the time or the volume of the bed is zero, which is not in accordance with reality (Yan et al., 2001).

\section{INVERSE PROBLEMS}

\subsection{Sensitivity analysis}

Prior to solving the inverse problem, it is necessary to analyze the reduced sensitivity coefficients of the model parameters. This analysis allows us to evaluate which parameters can be successfully estimated since the low magnitude of sensitivity or the presence of linear dependence between the parameters points to the existence of several solutions to the same problem (Orlande et al, 2011; Naveira-Cotta, 2009). This directly interferes 
with the estimation of the parameters, as the problem is classified as poorly conditioned. Thus, it is desirable that the parameters have high sensitivity and are not linearly dependent on each other to obtain an accurate estimate of them.

The partial derivatives of the state variable $\mathbf{C} / \mathbf{C}_{0}$, measured over time $\mathbf{t}=\{1, \ldots, \mathrm{TF}\}$, in relation to the know parameters $\boldsymbol{\theta}_{\mathbf{j}}$ for $\mathrm{j}=\{1, \ldots, \mathrm{NP}\}$ calculated by centered finite differences can be used to determine the reduce sensivity coefficients using Equation (7) with NP parameters, and perturbation $\varepsilon_{\mathrm{p}}$ (Orlande et al, 2011).

$$
\mathrm{J}_{\theta_{\mathrm{j}}}=\frac{\frac{\mathrm{C}}{\mathrm{C}_{0}}\left(\theta_{1}, \ldots, \theta_{\mathrm{j}}+\varepsilon_{\mathrm{r}} \theta_{\mathrm{j}}, \ldots, \theta_{\mathrm{NP}}\right)-\frac{\mathrm{C}}{\mathrm{C}_{0}}\left(\theta_{1}, \ldots, \theta_{\mathrm{j}}-\varepsilon_{\mathrm{r}} \theta_{\mathrm{j}}, \ldots, \theta_{\mathrm{NP}}\right)}{2 \varepsilon}
$$

\subsection{Bayes Theorem}

In Bayesian inference, there is an unknown amount of interest $\boldsymbol{\theta}$. To obtain more information about its probability distribution, just observe the sample distribution of an observable random variable, which in this case is the breakthrough curve $\mathbf{C} / \mathbf{C}_{\mathbf{0}}$, related to the parameters $\boldsymbol{\theta}$ which is mathematically described by the likelihood function $\mathrm{L}\left(\mathbf{C} / \mathbf{C}_{\mathbf{0}} \mid \boldsymbol{\theta}\right)$.

This way, the Baye's Theorem quantify the update of information, this is represented in the Eq. (8) (Ehlers, 2011):

$$
\pi_{\text {posterior }}\left(\boldsymbol{\theta} \mid \mathbf{C} / \mathbf{C}_{\mathbf{0}}\right)=\frac{\mathrm{L}\left(\mathbf{C} / \mathbf{C}_{\mathbf{0}} \mid \boldsymbol{\theta}\right) \pi_{\text {prior }}(\boldsymbol{\theta})}{\mathrm{f}(\mathbf{X})}
$$

The result is reflected in the posterior distribution $\pi_{\text {posterior }}\left(\boldsymbol{\theta} \mid \mathbf{C} / \mathbf{C}_{\mathbf{0}}\right)$, that is, the probability distribution of the parameter vector $\boldsymbol{\theta}=\left[\theta_{1}, \ldots, \theta_{\mathrm{NP}}\right]$ after observing the measurement values of the breakthrough curve $\mathbf{C} / \mathbf{C}_{\mathbf{0}}=\left[\left(\mathrm{C} / \mathrm{C}_{0}\right)_{1}, \ldots,\left(\mathrm{C} / \mathrm{C}_{0}\right)_{\mathrm{TF}}\right]$ over time $\mathbf{t}=[1, \ldots, \mathrm{TF}]$,

$\mathrm{f}(\mathbf{X})$ being the marginal density, which performs the function of normalization constant, and $\pi_{\text {prior }}(\theta)$ the a priori probability distribution. For this study, the vectors with the parameters to be estimated are: $\boldsymbol{\theta}^{\mathrm{T}}=\left[\mathrm{q}_{\mathrm{TH}}, \mathrm{k}_{\mathrm{TH}}\right]$ for the Thomas Model; $\boldsymbol{\theta}^{\mathrm{T}}=\left[\mathrm{k}_{\mathrm{YN}}, \tau\right]$ for the Yoon-Nelson Model; $\boldsymbol{\theta}^{\mathrm{T}}=[\mathrm{A}, \mathrm{r}, \mathrm{n}]$ for the Clark Model and $\boldsymbol{\theta}^{\mathrm{T}}=\left[\mathrm{q}_{\mathrm{Y}}, \mathrm{a}_{\mathrm{Y}}\right]$ for the Yan Model.

Thus, the posteriori probability density function can be written as being proportional to the product of likelihood and a priori distribution, shown in Eq. (9):

$$
\pi_{\text {posterior }}\left(\boldsymbol{\theta} \mid \mathbf{C} / \mathbf{C}_{\mathbf{0}}\right) \alpha \mathrm{L}\left(\mathbf{C} / \mathbf{C}_{\mathbf{0}} \mid \boldsymbol{\theta}\right) \mathrm{f}(\boldsymbol{\theta})
$$

The likelihood function can be rigorously formulated based on the probabilistic structure of errors provided by the difference between simulated and observed concentrations. When it is assumed that errors are normally distributed, independent and homoscedastic, the formal probability can be given according to Eq. (10) (Choi et al., 2019):

$$
L\left(\frac{\mathbf{C}}{\mathbf{C}_{\mathbf{0}}} \mid \boldsymbol{\theta}\right)=\frac{1}{\sqrt{2 \pi \sigma_{\text {meas }}^{2}}} \exp \left\{-\frac{\sum_{\mathrm{t}=1}^{\mathrm{TF}}\left[\left(\frac{\mathbf{C}}{\mathbf{C}_{\mathbf{0}}}\right)_{\mathrm{t}}-\left(\frac{\mathbf{C}}{\mathbf{C}_{\mathbf{0}}}\right)_{\mathrm{t}}^{\text {meas }}\right]^{2}}{2 \sigma_{\text {meas }}^{2}}\right\}
$$

where $\sigma_{\text {meas }}^{2}$ is the variance of the uncertainty of the measures.

\subsection{Monte Carlo Via Markov Chain}

In this work, to obtain an approximation of the posterior distribution, the Monte Carlo method with Markov Chain (MCMC) was used, simulating samples of $\pi_{\text {posterior }}\left(\boldsymbol{\theta} \mid \mathbf{C} / \mathbf{C}_{\mathbf{0}}\right)$. The objective was to obtain a sample of the distribution posteriori and calculate sample estimates of characteristics of this distribution.

Therefore, the Metropolis-Hastings algorithm was used. This algorithm is based on the acceptancerejection method, where candidate $\boldsymbol{\theta}^{*}$ values are generated that belong to a proposal distribution $\mathrm{p}\left(\boldsymbol{\theta}^{*} \mid \boldsymbol{\theta}^{(\mathrm{i}-1)}\right)$. In this work, Gaussian distributions were

used. The Metropolis-Hastings algorithm is described as (Metropolis et al, 1953; Hastings, 1970; Kaipio e Somersalo, 2004; Gamerman e Lopes, 2006; Orlande et al, 2011):

1. The chain iteration counter was started and an initial value was arbitrated $\theta^{(0)}$;

2. A candidate $\boldsymbol{\theta}^{*}$ of the distribution was generated $\mathrm{p}\left(\boldsymbol{\theta}^{*} \mid \boldsymbol{\theta}^{(\mathrm{i}-1)}\right)$ such that:

$$
\boldsymbol{\theta}^{*}=\boldsymbol{\theta}^{(\mathrm{i}-1)}(1+\mathrm{w} \varepsilon)
$$

where $\varepsilon$ is a random number from a normal distribution, $\mathrm{N}(0,1)$, and $\mathrm{w}$ is the search step;

3. The probability of acceptance was calculated $\alpha\left(\boldsymbol{\theta}^{(\mathrm{i}-1)} \mid \boldsymbol{\theta}^{*}\right)$ candidate value in the form:

$$
\alpha\left(\boldsymbol{\theta}^{(\mathrm{i}-1)} \mid \boldsymbol{\theta}^{*}\right)=\min \left[1, \frac{\mathrm{f}\left(\boldsymbol{\theta}^{*} \mid \mathbf{C} / \mathbf{C}_{\mathbf{0}}\right)}{\mathrm{f}\left(\boldsymbol{\theta}^{(\mathrm{i}-1)} \mid \mathbf{C} / \mathbf{C}_{\mathbf{0}}\right)}\right]
$$

4. A random number $u$ with uniform distribution was generated, i.e $\mathrm{u} \sim \mathrm{U}(0,1)$;

5. If $\mathrm{u} \leq \alpha\left(\boldsymbol{\theta}^{(\mathrm{i}-1)} \mid \boldsymbol{\theta}^{*}\right)$, the new parameter vector has been accepted and $\boldsymbol{\theta}^{(i+1)}=\boldsymbol{\theta}^{*}$. Otherwise, $\boldsymbol{\theta}^{(i+1)}=\boldsymbol{\theta}^{(\mathrm{i})}$;

6. The counter was increased from $i$ to $i+1$ and returned to step 2 . 


\subsection{Model Selection}

The selection of the model that best fitted the experimental data was based on the minimization of three Bayesian statistical criteria. The Akaike criterion (AIC) introduces the distance between probability densities between the unknown model and the candidate model from the Kullback-Leibler divergence estimate (Akaike, 1974; Loos, 2016), as shown in Equation (13).

$$
\mathrm{AIC}=-2 \log \left[\mathrm{L}\left(\mathbf{C} / \mathbf{C}_{0} \mid \boldsymbol{\theta}\right)\right]+2 \mathrm{NP}
$$

where NP is the number of parameters to be estimated in the model.

Bozdogan (1987) proposed a correction for the AIC $\left(\mathrm{AIC}_{\text {corr }}\right)$, shown in Equation (14), in which the number of observations in the $J$ sample was inserted.

$$
\mathrm{AIC}_{\text {Corr }}=\mathrm{AIC}+2 \frac{\mathrm{NP}(\mathrm{NP}+1)}{\mathrm{J}-\mathrm{NP}-1}
$$

Finally, the Bayesian Information Criterion (BIC) proposed by Schwarz (1978) chooses the model that minimizes the Eq. (15):
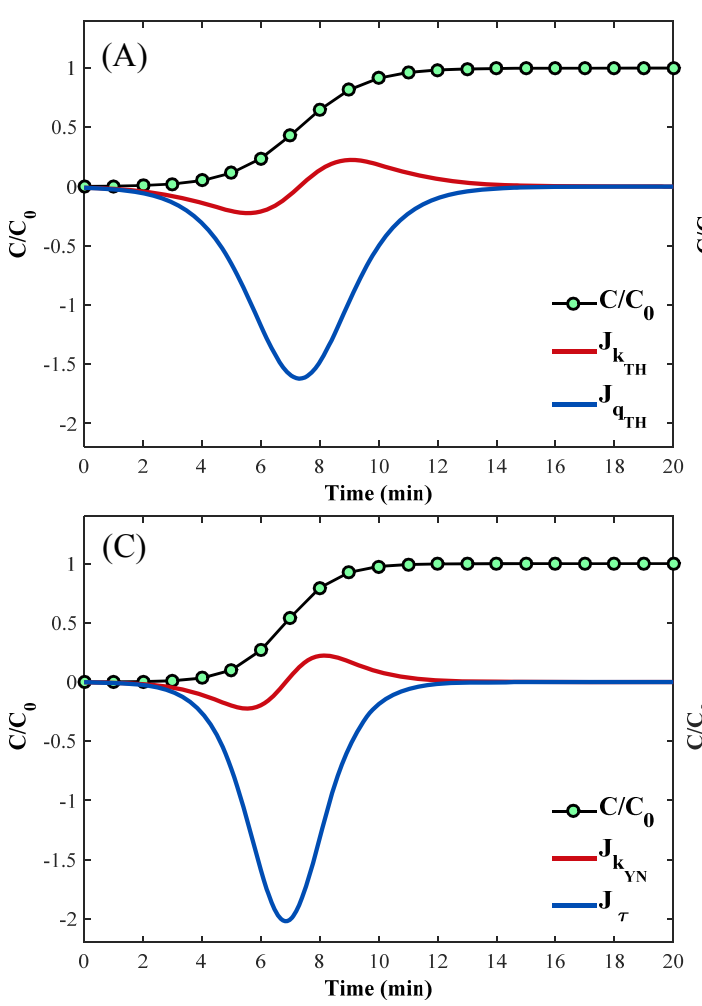

Figure 1. Reduced sensitivity coefficient for models of (A) Thomas, (B) Clark, (C) Yoon-Nelson e (D) Yan.

In the sequence, the results are presented using the Monte Carlo method via Markov chain as a technique for solving the inverse problem of estimating parameters of the rupture curves obtained

$$
\mathrm{BIC}=-2 \log \left[\mathrm{L}\left(\mathbf{C} / \mathbf{C}_{0} \mid \boldsymbol{\theta}\right)\right]+\mathrm{NP} \log (\mathrm{J})
$$

\section{RESULTS AND DISCUSSION}

The application of the Bayesian approach to the problem of estimating parameters of the rupture curve of the data collected by Ang et al. (2019) followed the order of previously analyzing the reduced sensitivity coefficient followed by the results of the parameter estimates, rupture curve and model selection.

Figure 1 shows the results of the reduced sensitivity coefficients $\mathrm{J}_{\theta \mathrm{j}}$ for each parameter of the models and the exact solution $\mathbf{C} / \mathbf{C}_{0}$ in $Z=5 \mathrm{~cm}$.

Analyzing the curves, it is observed that it was possible to estimate all parameters of the Thomas, Yoon-Nelson, and Yan models since they presented high sensitivity and are linearly independent.

However, there was a low sensitivity for parameter A of the Clark model, making it impossible to simultaneously estimate the three parameters. For these reasons, only $r$ and $n$ were chosen as satisfactory to perform the estimate, while the other was maintained deterministically.
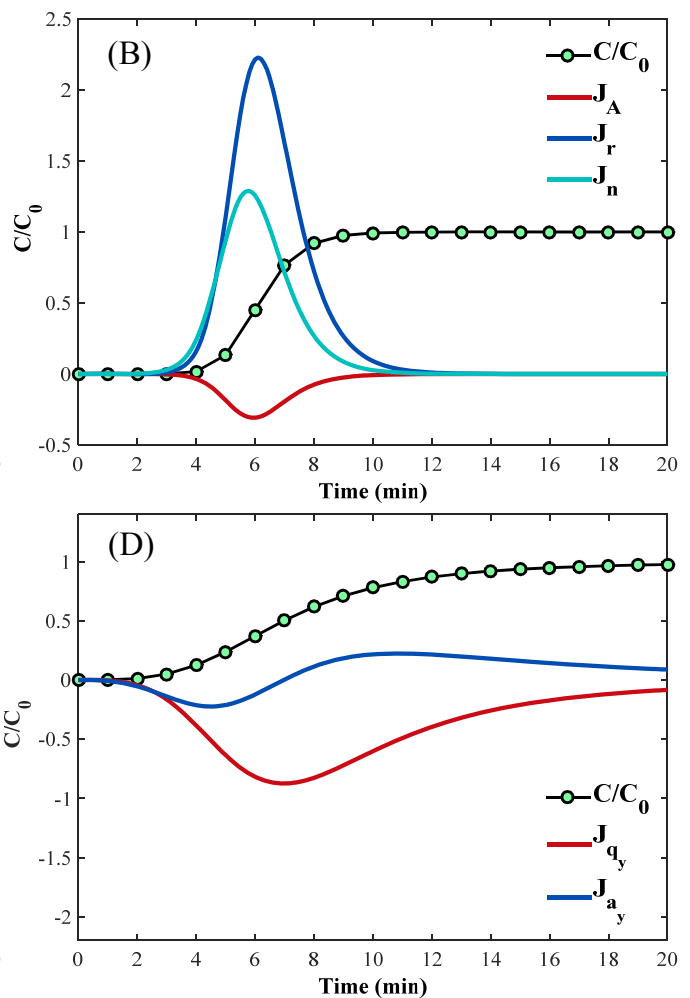

by Ang et al. (2019) in which the height of the $\mathrm{z}$ bed was varied.

The a prior probability distribution was adopted as normal $\mathrm{N}\left(\theta_{\text {ref }}, \sigma^{2}\right)$. Regarding the statistics, for the

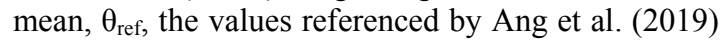


for the parameters of the Thomas and Yoon-Nelson models; while for the Clark and Yan models the values are shown in Table 1. Regarding the uncertainties, the standard deviation was $30 \%$ of this average, the measurement uncertainty used in Equation 10 was considered to be equivalent to $5 \%$ of the maximum of the experimental measure $\mathbf{C} / \mathbf{C}_{0}$, the search step $\mathrm{w}=0.005$ and 50,000 states of the Markov Chain.

The Markov chains for these estimates are shown in Figures 2 and 3. Notably, the burn-in states of the chains were overcome after approximately 2000 states in all simulated cases.

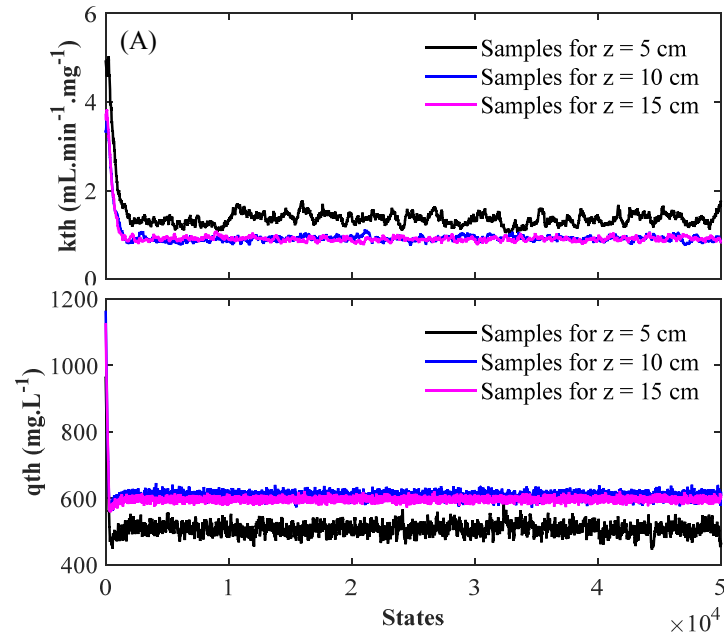

Figure 2. Cadeias para o modelo de Thomas (A) e modelo de Clark (B).
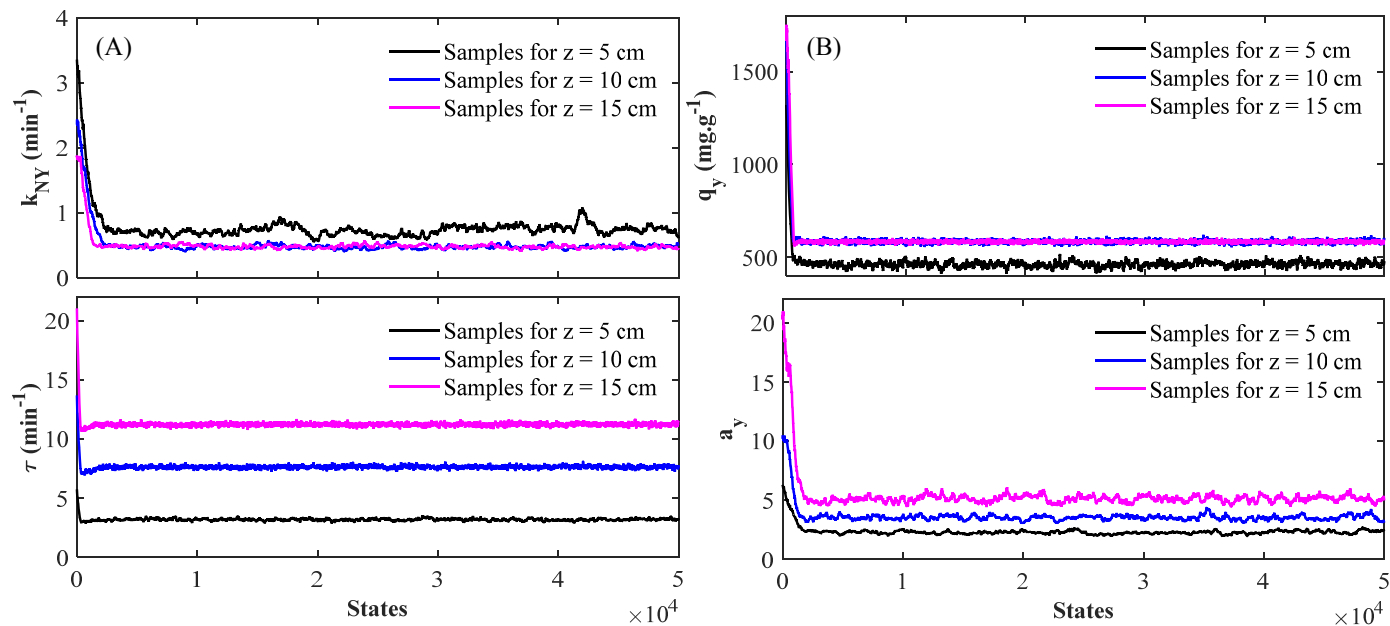

Figure 3. Chains for the Yoon-Nelson model (A) and Yan model (B).

The statistics of the posterior probability distribution of the parameters, as well as the comparison with the values of Ang et al. (2019), are presented in Tables 2-5. In this work, only the average and $99 \%$ credibility interval of a posteriori probability distribution of the parameters is reported.

When analyzing the estimates of the parameters presented in Tables 2-5, it was found that the parameters $\mathrm{k}_{\mathrm{YN}}$ (Yoon-Nelson) and $\mathrm{k}_{\mathrm{TH}}$ (Thomas)
Table 1. Average of the a priori distribution of the parameters of the Clark and Yan models.

\begin{tabular}{c|c|c|c|c|c}
\hline $\mathrm{z}(\mathrm{cm})$ & $\mathrm{A}$ & $\mathrm{r}\left(\mathrm{min}^{-1}\right)$ & $\mathrm{n}$ & $\mathrm{q}_{\mathrm{y}}\left(\mathrm{mg} \mathrm{g}^{-1}\right)$ & $\mathrm{a}_{\mathrm{y}}$ \\
\hline 5 & 90 & 2.2 & 1.1 & 440 & 2.1 \\
10 & 500 & 1.2 & 1.4 & 555 & 3.5 \\
15 & 5000 & 0.7 & 1.8 & 580 & 6.9 \\
\hline
\end{tabular}

From that point on, it was observed that the chains converged to the equilibrium distribution, and the estimates are represented by these Markov chain states, as these representative samples of the posteriori probability distribution of the parameters.
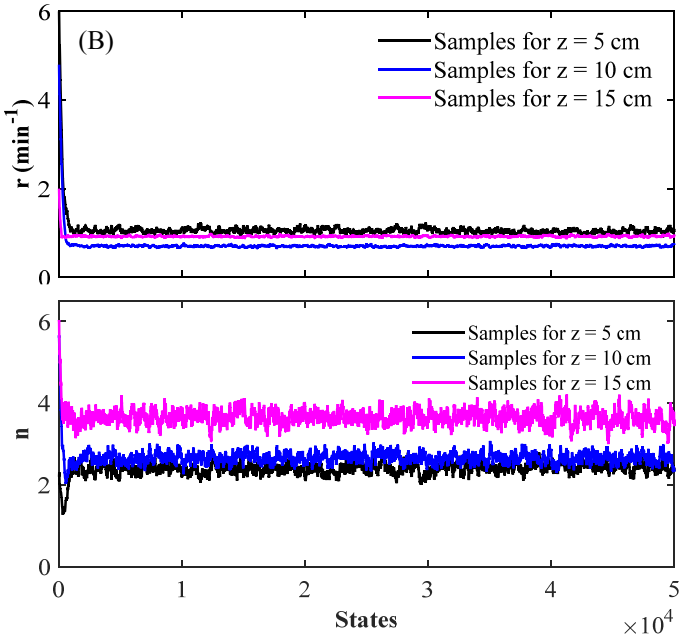

$10^{4}$ 
uncertainties associated with the estimates, it can be said that in all the estimates there was a low degree of uncertainty when comparing the range of the $99 \%$ credibility interval with the average of the estimates.

Table 2. Comparison and parameter estimates for the Yoon-Nelson model.

\begin{tabular}{c|c|c|c|c}
\hline $\begin{array}{c}\mathrm{z} \\
(\mathrm{cm})\end{array}$ & Parameter & $\begin{array}{c}\text { Ang } \\
\text { et al. } \\
(2019)\end{array}$ & Present work & $\begin{array}{c}\text { Rel. } \\
\text { Dev. } \\
(\%)\end{array}$ \\
\hline \multirow{2}{*}{5} & $\mathrm{k}_{\mathrm{YN}}\left(\mathrm{min}^{-1}\right)$ & 1.68 & $0.75(0.60 ; 0.95)$ & 55.35 \\
\hline \multirow{2}{*}{10} & $\tau\left(\mathrm{min}^{-1}\right)$ & 2.87 & $3.21(2.96 ; 3.45)$ & 11.84 \\
\hline \multirow{2}{*}{15} & $\tau\left(\mathrm{min}^{-1}\right)$ & 1.18 & $0.48(0.42 ; 0.58)$ & 59.32 \\
& $\mathrm{k}_{Y N}\left(\mathrm{~min}^{-1}\right)$ & 0.85 & $7.63(7.33 ; 7.95)$ & 11.39 \\
\hline
\end{tabular}

Table 3. Comparison and parameter estimates for the Thomas model.

\begin{tabular}{|c|c|c|c|c|}
\hline $\begin{array}{c}\mathrm{z} \\
(\mathrm{cm})\end{array}$ & Parameter & $\begin{array}{c}\text { Ang et } \\
\text { al. } \\
(2019)\end{array}$ & Estimate & $\begin{array}{l}\text { Rel. } \\
\text { Dev. } \\
(\%)\end{array}$ \\
\hline \multirow{2}{*}{5} & 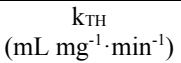 & 2.47 & $\begin{array}{c}1.43 \\
(1.19 ; 1.73)\end{array}$ & 42.10 \\
\hline & $\begin{array}{c}\mathrm{q}_{\mathrm{TH}} \\
\left(\mathrm{mg} \mathrm{g}^{-1}\right) \\
\end{array}$ & 482.29 & $\begin{array}{c}509.73 \\
(469.35 ; 549.62) \\
\end{array}$ & 5.69 \\
\hline \multirow{2}{*}{10} & $\begin{array}{c}\mathrm{k}_{\mathrm{TH}} \\
\left(\mathrm{mL} \mathrm{m}^{-1} \cdot \mathrm{min}\right)\end{array}$ & 1.68 & $\begin{array}{c}0.91 \\
(0.78 ; 1.06)\end{array}$ & 45.83 \\
\hline & $\begin{array}{c}\mathrm{q} \text { TH } \\
\left(\mathrm{mg} \mathrm{g}^{-1}\right)\end{array}$ & 582.28 & $\begin{array}{c}607.76 \\
(583.28 ; 632.96)\end{array}$ & 4.37 \\
\hline \multirow{2}{*}{15} & $\begin{array}{c}\mathrm{k}_{\mathrm{TH}} \\
\left(\mathrm{mL} \mathrm{mg}^{-1} \cdot \mathrm{min}\right)\end{array}$ & 1.87 & $\begin{array}{c}0.91 \\
(0.80 ; 1.10)\end{array}$ & 51.33 \\
\hline & $\begin{array}{c}\mathrm{q}_{\mathrm{TH}} \\
\left(\mathrm{mg} \mathrm{g}^{-1}\right)\end{array}$ & 563.83 & $\begin{array}{c}596.68 \\
(581.17 ; 613.66)\end{array}$ & 5.82 \\
\hline
\end{tabular}
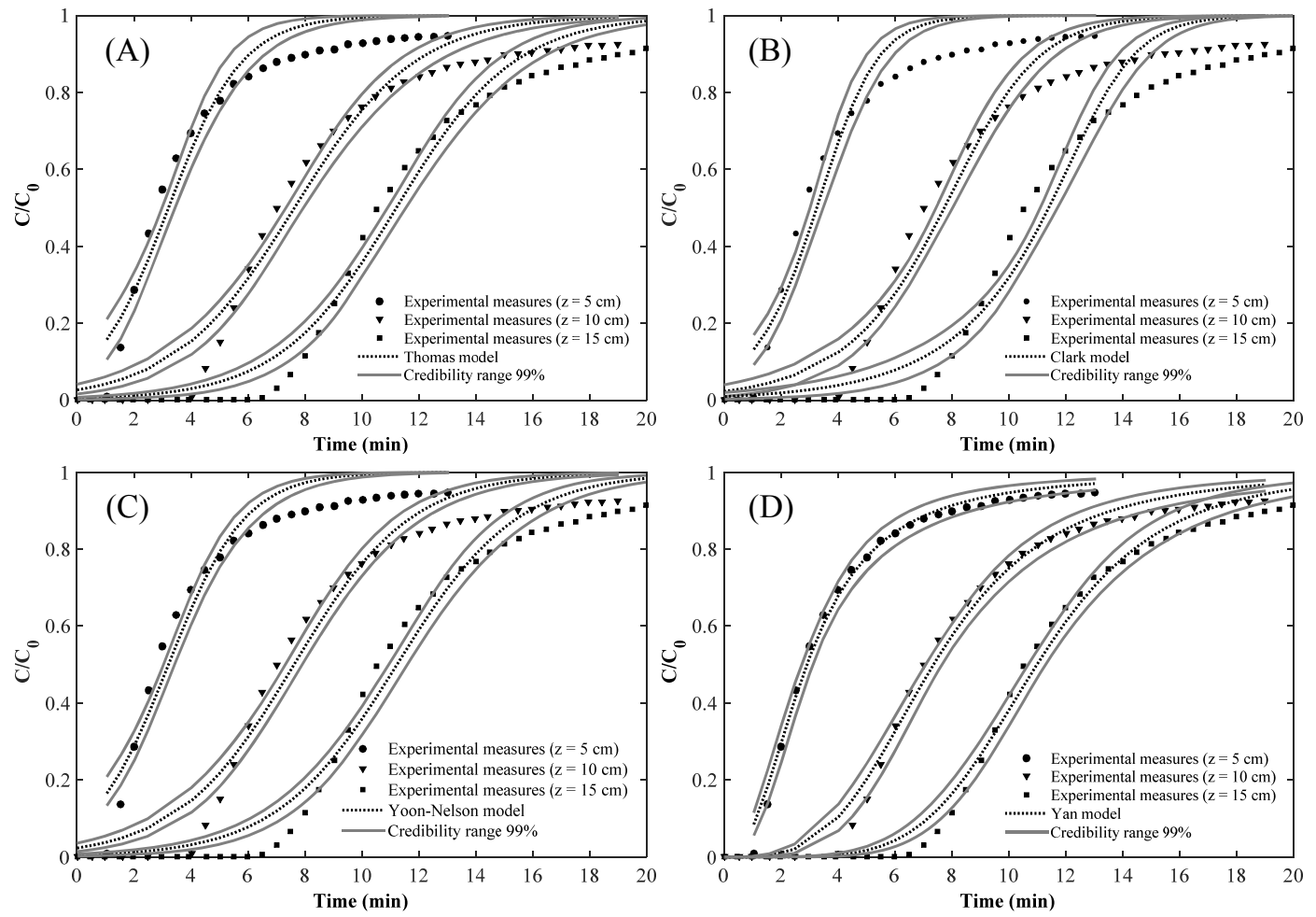

Figure 4. Breaking curve estimates for (A) Thomas, (B) Clark, (C) Yoon-Nelson and (D) Yan models.

In order to quantify the adjustment to the experimental data, the value of the Bayesian criteria
Table 4. Comparison and parameter estimates for the Clark model.

\begin{tabular}{c|c|c}
\hline $\mathrm{z}(\mathrm{cm})$ & Parameter & Estimate \\
\hline \multirow{2}{*}{5} & $\mathrm{r}\left(\mathrm{min}^{-1}\right)$ & $1.061(0.942 ; 1.202)$ \\
& $\mathrm{n}$ & $2.368(2.081 ; 2.658)$ \\
\hline \multirow{2}{*}{10} & $\mathrm{r}\left(\mathrm{min}^{-1}\right)$ & $0.703(0.657 ; 0.755)$ \\
& $\mathrm{n}$ & $2.660(2.362 ; 2.956)$ \\
\hline \multirow{2}{*}{15} & $\mathrm{r}\left(\mathrm{min}^{-1}\right)$ & $0.921(0.878 ; 0.964)$ \\
& $\mathrm{n}$ & $3.674(3.283 ; 4.085)$ \\
\hline
\end{tabular}

Table 5. Comparison and parameter estimates for the Yan model.

\begin{tabular}{c|c|c}
\hline $\mathrm{z}(\mathrm{cm})$ & Parameter & Present study \\
\hline \multirow{2}{*}{5} & $\mathrm{q}_{\mathrm{y}}\left(\mathrm{mg} \mathrm{g}^{-1}\right)$ & $465.32(437.21 ; 494.33)$ \\
& $\mathrm{a}_{\mathrm{y}}$ & $2.34(2.09 ; 2.65)$ \\
\hline \multirow{2}{*}{10} & $\mathrm{q}_{\mathrm{y}}\left(\mathrm{mg} \mathrm{g}^{-1}\right)$ & $583.95(559.91 ; 607.59)$ \\
& $\mathrm{a}_{\mathrm{y}}$ & $3.51(3.06 ; 3.99)$ \\
\hline \multirow{2}{*}{15} & $\mathrm{q}_{\mathrm{y}}\left(\mathrm{mg} \mathrm{g}^{-1}\right)$ & $583.84(568.00 ; 599.11)$ \\
& $\mathrm{a}_{\mathrm{y}}$ & $5.13(4.44 ; 5.86)$ \\
\hline
\end{tabular}

The estimated and experimental breakthrough curves are shown in Figure 4. From the result, a good agreement was observed between the experimental and estimated data for the Yan model, which is mostly contained within the credibility interval in. $z=5 \mathrm{~cm}$. 
study with those of Ang et al. (2019) for Thomas and Yoon-Nelson models.

Table 6: Statistical metrics for model selection at $\mathrm{z}=$ $5 \mathrm{~cm}$.

\begin{tabular}{c|c|c|c}
\hline Metric & Model & $\begin{array}{c}\text { Present } \\
\text { study }\end{array}$ & $\begin{array}{c}\text { Ang et al. } \\
(2019)\end{array}$ \\
\hline \multirow{4}{*}{ AIC } & Thomas & 54.125 & 95.899 \\
& Yoon-Nelson & 54.294 & 133.422 \\
& Clark & 70.119 & --- \\
\hline \multirow{4}{*}{ AIC ${ }_{\text {corr }}$} & Yan & 10.435 & --- \\
& Thomas & 54.671 & 96.421 \\
& Yoon-Nelson & 54.839 & 133.944 \\
& Clark & 70.664 & --- \\
BIC & Yan & 10.980 & --- \\
\hline & Thomas & 28.281 & 49.208 \\
& Yoon-Nelson & 28.366 & 67.969 \\
& Clark & 36.278 & --- \\
\hline
\end{tabular}

Table 7: Statistical metrics for model selection at $\mathrm{z}=$ $10 \mathrm{~cm}$.

\begin{tabular}{c|c|c|c}
\hline Metric & Model & $\begin{array}{c}\text { Present } \\
\text { study }\end{array}$ & $\begin{array}{c}\text { Ang et al. } \\
(2019)\end{array}$ \\
\hline \multirow{4}{*}{ AIC } & Thomas & 74.288 & 160.435 \\
& Yoon-Nelson & 74.539 & 256.924 \\
& Clark & 105.625 & --- \\
\hline \multirow{4}{*}{ AICcorr } & Yan & 23.500 & --- \\
\hline \multirow{4}{*}{ BIC } & Thomas & 74.651 & 160.798 \\
& Yoon-Nelson & 74.903 & 257.287 \\
& Clark & 105.988 & --- \\
& Yan & 23.863 & --- \\
\hline & Thomas & 38.727 & 81.801 \\
& Clark & 38.853 & 130.045 \\
& Yan & 13.333 & --- \\
\hline
\end{tabular}

According to the model selection criteria, the estimate by the Bayesian technique presented a better result in relation to the study by Ang et al. (2019), because in all the studied cases, lower values for the Bayesian metrics were obtained. This fact corroborates the high value of the relative deviation discussed above.

Table 8: Statistical metrics for model selection at $\mathrm{z}=$ $15 \mathrm{~cm}$.

\begin{tabular}{c|c|c|c}
\hline Metric & Model & $\begin{array}{c}\text { Present } \\
\text { study }\end{array}$ & $\begin{array}{c}\text { Ang et al. } \\
(2019)\end{array}$ \\
\hline \multirow{4}{*}{ AIC } & Thomas & 64.879 & 208.596 \\
& Yoon-Nelson & 64.865 & 198.020 \\
& Clark & 131.191 & --- \\
\hline \multirow{4}{*}{ AICcorr } & Yan & 25.320 & --- \\
\hline \multirow{4}{*}{ BIC } & Thomas & 65.195 & 208.912 \\
& Yoon-Nelson & 65.180 & 198.336 \\
& Clark & 131.507 & --- \\
& Yan & 25.633 & --- \\
\hline & Thomas & 34.153 & 106.012 \\
& Yoon-Nelson & 34.146 & 100.724 \\
& Clark & 67.309 & --- \\
\hline
\end{tabular}

From the results, it was observed that the Yan model presented the best quantitative estimate with the lowest value for the three Bayesian criteria, mainly in. It is worth mentioning that for this bed height, the best estimates were obtained for all models, indicating that they better represent the phenomenon of adsorption in shorter break times.

In addition, it was observed that the Thomas and Yoon-Nelson models presented similar estimates (because they present close values for the metrics $\mathrm{AIC}, \mathrm{AIC}_{\text {corr }}$ and $\left.\mathrm{BIC}\right)$, and, according to the selection criteria, the adjustment to the Yoon model Nelson overcame the first only when. This is due to the fact that both models are very mathematically similar. However, it is known that the Yoon-Nelson model is the simplest among those analyzed, but the Thomas model loses accuracy for long periods. As reported in the literature, this deficiency is overcome by Yan's model (De Franco et al., 2017).

Among the models studied, the Clark model stands out among the others due to the high values of the Bayesian metrics used (AIC, $\mathrm{AIC}_{\text {corr }}$, and $\mathrm{BIC}$ ), indicating the worst estimate for the rupture curves.

\section{CONCLUSION}

In this work, the problem of estimating parameters of fixed-bed adsorption was solved, using Bayesian techniques. As a solution methodology, the analytical models of Thomas, Yoon-Nelson, Clark, and Yan were adjusted to experimental data provided in the literature using the Monte Carlo Bayesian technique via Markov Chain implemented with the Metropolis-Hastings acceptance/rejection algorithm. Based on the sensitivity analysis, it was observed that most of the parameters analyzed can be easily estimated, directly implicating the convergence of Markov chains.

Regarding the estimates, the models presented a good fit to the experimental curves, however, the Yan model was more adequate to represent the experimental data and this was the model selected by the Bayesian criteria. Therefore, the Bayesian approach presented itself as an advantageous alternative for the estimation of parameters and selection of models, thus consequently for the prediction of the characteristics of the adsorption system.

\section{ACKNOWLEDGMENT}

The authors thanks to the National Council of Technological and Scientific Development (CNPq) and the Coordination for the Improvement of High Education Personnel (CAPES) of the Brazilian Government for the financial support granted to carry out this work.

\section{REFERENCES}

Akaike, H., 1974 A new look at the statistical model identification. IEEE Transactions on Automatic Control., Boston, 19(6), 716-723. 
Aksu, Z., Gönen, F., 2004. Biosorption of phenol by immobilized activated sludge in a continuous packed bed: prediction of breakthrough curves. Process biochemistry, 39(5), 599-613.

Ang, T. N., Young, B. R., Taylor, M., Burrell, R., Aroua, M. K., Baroutian, S., 2020, Breakthrough analysis of continuous fixed-bed adsorption of sevoflurane using activated carbons, Chemosphere, 239, 124839.

Bhaumik, M. Setshedi, K. Maity, A. Onyango, M. S., 2013. Chromium(VI) removal from water using fixed bed column of polypyrrole $/ \mathrm{Fe}_{3} \mathrm{O}_{4}$ nanocomposite Sep, Purif. Technol. 110 11-19.

Bonilla-Petriciolet, A., Mendoza-Castillo, D. I., Reynel-Ávila, H. E. (Eds.)., 2017. Adsorption processes for water treatment and purification. Netherlands: Springer.

Borna, M. O., Pirsaheb, M., Niri, M. V., Mashizie, R. K., Kakavandi, B., Zare, M. R., Asadi, A., 2016, Batch and column studies for the adsorption of chromium (VI) on low-cost Hibiscus Cannabinus kenaf, a green adsorbent. Journal of the Taiwan Institute of Chemical Engineers, 68, 80-89.

Bozdogan, H., 1987 Model selection and Akaike's information criterion (AIC): The general theory and its analytical extensions. Psychometrica. 52, 345-370.

Chu, K. H., 2010, Fixed bed sorption: setting the record straight on the Bohart-Adams and Thomas models. Journal of Hazardous Materials, 177, 10061012.

Clark, R. M., 1987, Evaluating the cost and performance of field-scale granular activated carbon systems. Environmental science \& technology, 21, 573-580.

De Franco, M.A.E., de Carvalho, C.B., Bonetto, M.M., Soares, R. de P., Féris, L.A., 2017. Removal of amoxicillin from water by adsorption onto activated carbon in batch process and fixed bed column: kinetics, isotherms, experimental design and breakthrough curves modelling. J. Clean. Prod. 161, 947-956.

Ehlers, R. S., 2011, Inferência bayesiana. Departamento de Matemática Aplicada e Estatistica, ICMC-USP, 64.

Gamerman, D., Lopes, H., Markov, H., 2006. Chain Monte Carlo: Stochastic simulation for Bayesian inference, London: Chapman \& Hall, 2006.

Hastings, W., 1970. Monte Carlo Sampling Methods using Markov Chains and their Applications, Biometrika, 57, 97-109.

Jain, S. N., Tamboli, S. R., Sutar, D. S., Jadhav, S. R., Marathe, J. V., Shaikh, A. A., Prajapati, A. A., 2019, Batch and continuous studies for adsorption of anionic dye onto waste tea residue: Kinetic, equilibrium, breakthrough and reusability studies. Journal of Cleaner Production, 252, 119778.

Jaria, G., Calisto, V., Silva, C. P., Gil, M. V., Otero, M., Esteves, V. I., 2019, Fixed-bed performance of a waste-derived granular activated carbon for the removal of micropollutants from municipal wastewater. Science of the Total Environment, 683, 699-708.

Kaipio, J., Somersalo, E., 2004. Computational and Statistical Methods for Inverse Problems, Springer, Berlin.

Lima, A. C. A., 2009 Adsorção de ânions presente em efluente usando pó da casca de coco verde modificado. 90 f. Dissertação (Mestrado em Saneamento Ambiental) - Pós-graduação em Engenharia Civil da Universidade Federal do Ceará, Fortaleza, 2009.

Liu, M., Li, X., Du, Y., Han, R., 2019. Adsorption of methyl blue from solution using walnut shell and reuse in a secondary adsorption for Congo red. Bioresource Technology Reports, 5, 238242.

Loos, C., 2016 Analysis of Single-Cell Data: ODE Constrained Mixture Modeling and Approximate Bayesian Computation.

Luz, A. D. D. Aplicação de coluna de adsorção em leito fixo para a remoção de compostos BTX multicomponentes presentes em efluentes petroquímicos. Dissertação. Tese de Doutorado. Universidade Federal de Santa Catarina, Centro Tecnológico. Programa de Pós-Graduação em Engenharia Química. Florianópolis, SC, 2012.

Metropolis, N. Rosenbluth, A. Rosenbluth, M. Oliveira, C., Junior, J. L., Knupp, D. C., Neto, A. S., Prieto-Moreno, A., Llanes-Santiago, O. (2018). Estimation of kinetic parameters in a chromatographic separation model via Bayesian inference. Revista Internacional de Métodos Numéricos para Cálculo y Diseño en Ingeniería, 34(1).

Mthombeni, N. H., Mbakop, S., Ray, S. C., Leswifi, T., Ochieng, A., Onyango, M. S., 2018. Highly efficient removal of chromium (VI) through adsorption and reduction: a column dynamic study using magnetized natural zeolite-polypyrrole composite. Journal of Environmental Chemical Engineering, 6(4), 4008-4017.

Nakkeeran, E., Patra, C., Shahnaz, T., Rangabhashiyam, S., Selvaraju, N. J. B. T. R., 2018. Continuous biosorption assessment for the removal of hexavalent chromium from aqueous solutions using Strychnos nux vomica fruit shell. Bioresource Technology Reports, 3, 256-260.

Nascimento, R. F. D., Lima, A. C. A. D., Vidal, C. B., Melo, D. D. Q., Raulino, G. S. C. 2014. Adsorção: aspectos teóricos e aplicações ambientais.

Naveira-Cotta, C. P. Problemas inversos de condução de calor em meios heterogêneos: análise teórico-experimental via transformação integral, inferência bayesiana e termografia por infravermelho. 2009. Tese de Doutorado. Tese, Rio de janeiro, UFRJ/COPPE.

Orlande, H. R. B., Fudym, O., Maillet, D., Cotta, R. M., Thermal Measurements and Inverse Techniques, CRC Press, Boca Raton, 2011. 
Radhika, R., Jayalatha, T., Jacob, S., Rajeev, R., George, B. K., 2018, Adsorption performance of packed bed column for the removal of perchlorate using modified activated carbon. Process Safety and Environmental Protection, 117, 350-362.

Schwarz, G. 1978, Estimating the dimensional of a model. Annals of Statistics, Hayward, 6(2), 461464.

Shanmugam, D., Alagappan, M., Rajan, R. K., 2016. Bench-scale packed bed sorption of Cibacron blue F3GA using lucrative algal biomass. Alexandria Engineering Journal, 55(3), 2995-3003.

Teller, A. Teller, E., 1953. Equation of State Calculation by Fast Computing Machines, J. Chemical Phys., 21, 1087-1092.

Thomas, H.C., 1944, Heterogeneous ion exchange in a flowing system, Journal of the American Chemical Society, 66, 1664-1666.

Van Ravenzwaaij, D., Cassey, P., Brown, S. D., 2018. A simple introduction to Markov Chain Monte-Carlo sampling. Psychonomic bulletin \& review, 25(1), 143-154.

Xu, Z., Cai, J. G., Pan, B. C., 2013, Mathematically modeling fixed-bed adsorption in aqueous systems. Journal of Zhejiang University Science A, 14, 155-176.

Weber, W. J., Smith, E. H.,1987. Simulation and design models for adsorption processes. Environmental science \& technology, 21(11), 10401050 . 